\title{
环二肽合酶生物合成途径研究进展
}

\author{
张京星 $^{a}$ 姚婷婷 ${ }^{a}$ 刘 晶 ${ }^{a}$ 李花月 $a, b$ 李文利*,a,b \\ ( ${ }^{a}$ 中国海洋大学医药学院 教育部海洋药物重点实验室 青岛 266003) \\ $\left({ }^{b}\right.$ 青岛海洋科学与技术国家实验室 海洋生物学与生物技术功能实验室 青岛 266237)
}

\begin{abstract}
摘要 二酮哌嗪类化合物(DKPs)的特征结构是由两个 $\alpha$-氨基酸通过肽键缩合而成的环二肽(CDPs), 稳定的六元环骨架 结构使 DKPs 在药物化学中成为一个重要的药效团, 表现出丰富的生物活性. 合成可作为药物先导物的 DKPs 已日益引 起人们的关注, 其中, 开展生物合成研究是拓宽其化学结构多样性的一个有效途径. 与早期阐明的非核糖体肽合成酶 (NRPSs)生物合成途径不同, 环二肽合酶(CDPSs) 以氨酰-tRNAs (aa-tRNAs)作为底物合成环二肽, 其后修饰过程发生在 环二肽形成之后. 目前国内外已研究的经 CDPS 途径合成的二酮哌嗪类化合物报道了 6 例. 对近年来环二肽合酶 (CDPSs)生物合成途径相关研究进展进行了综述.
\end{abstract}

关键词 二酮哌嗪类化合物; 非核糖体肽合成酶; 环二肽合酶; 生物合成途径

\section{Recent Advances in Cyclodipeptide Synthases-Dependent Biosynthetic Pathway}

\author{
Zhang, Jingxing $^{a} \quad$ Yao, Tingting $^{a} \quad$ Liu, Jing $^{a} \quad$ Li, Huayue $^{a, b} \quad$ Li, Wenli ${ }^{*, a, b}$ \\ ( ${ }^{a}$ Key Laboratory of Marine Drugs, Chinese Ministry of Education, School of Medicine and Pharmacy, \\ Ocean University of China, Qingdao 266003) \\ ( ${ }^{b}$ Laboratory for Marine Biology and Biotechnology, Qingdao National Laboratory for Marine Science and Technology, \\ Qingdao 266237)
}

\begin{abstract}
Diketopiperazines (DKPs) are derivatives of cyclodipeptides resulted from the condensation of two $\alpha$-amino acids. The conformationally constrained six-membered ring makes DKP an attractive pharmacophore in medicinal chemistry, exhibiting a wide range of bioactivities. Recently, there has been increased interests in synthesizing DKPs and biosynthesis is an effective pathway to broaden their structural diversity. Different from non-ribosomal peptide synthetases (NRPSs)-dependent pathways, cyclodipeptide synthases (CDPSs) use aminoacyl-tRNAs (aa-tRNAs) as substrates and the resulting cyclodipeptides are further modified by associated tailoring enzymes to yield the final products. To date, six CDPS-dependent pathways for synthesizing DKPs compounds have been reported. A brief overview of recent progresses on CDPS-dependent DKPs biosynthetic pathway is provided.
\end{abstract}

Keywords diketopiperazines; non-ribosomal peptide synthetases; cyclodipeptide synthases; biosynthetic pathway

二酮哌嗪类化合物(diketopiperazines, DKPs)的特征 结构是由两个 $\alpha$-氨基酸通过肽键缩合而成的最小环肽, 即环二肽(cyclic dipeptides or cyclodipeptides, CDPs). 肽 类天然产物是成药化合物重要的来源之一 ${ }^{[1,2]}$. 与其线 性类似物相比, DKPs 由于具有稳定的六元环结构, 良好 的蛋白酶抗性和构象刚性, 表现出抗细菌 ${ }^{[4,5]}$ 、抗真 菌 $^{[6,7]}$ 、抗病毒 ${ }^{[8]}$ 、抗肿瘤 ${ }^{[9,10]}$ 、免疫抑制 ${ }^{[11]}$ 、神经保 护 ${ }^{[12]}$ 、抗疮疾 ${ }^{[13]}$ 、抗朊病毒 $[14]$ 、抗高血糖 ${ }^{[15]}$, 以及作为
潜在的血脑屏障跨膜载体 ${ }^{[16]}$ 等多种显著的生物活性及 药理活性 ${ }^{[3,18]}$. 如 nocazine 家族 XR334 结构修饰后得到 的 XR5118 可逆转纤溶酶原激活物抑制剂-1 (plasminogen activator inhibitor-1, PAI-1)的抑制作用，表现出较好 的溶血栓作用，有望成为第四代溶栓药物 ${ }^{[22,16]}$; 具有显 著抗革兰氏阴性菌活性的双环霉素(bicyclomycin), 是 目前已知的唯一天然产物来源的转录终止因子 Rho 蛋 白的选择性抑制剂[55]; 在天然产物 phenylahistin 结构基

\footnotetext{
* Corresponding author. E-mail: liwenli@ouc.edu.cn

Received June 1, 2018; revised September 10, 2018; published online September 17, 2018.

Project supported by the National Natural Science Foundation of China (Nos. 31171201, 81561148012, 31570032).

国家自然科学基金(Nos. 31171201, 81561148012, 31570032)资助项目.
} 
础上, 经构效关系研究合成的海洋抗肿瘤候选药物普那 布林(plinabulin), 已进入临床三期研究 ${ }^{[17,18]}$; 分离自感 染疮痂病土豆切片的 thaxtomin A 目前已被美国环保署 登记为一种生物除草剂 ${ }^{[19]}$. 目前已进入临床使用的 DKPs 类药物有: 用于治疗肺动脉高压和勃起功能障碍 的它达拉非 (tadalafil) ${ }^{[20]}$ 以及催产素受体拮抗剂 epelsiban 等 ${ }^{[21]}$ (图 1). 同时, 基于 CDPs 的小分子量及较 强的跨膜运输能力, 已有研究人员提出 CDPs 可作为微 生物种内及种间群体感应的化学信号, 参与自然界中的 生物化学通讯现象. 如霍乱弧菌(Vibrio cholera)产生的 致病因子主要有两种: 霍乱毒素(cholera toxin, CT)和毒 素协同菌毛(toxin-coregulated pilus, TCP), 而这两种致 病因子的表达都受 ToxR 操纵子的调控, 由创伤弧菌 (Vibrio vulnificus)产生的 cyclo-( $L$-Phe- $L$-Pro) 能够下调 ToxR 操纵子以抑制 CT 和 TCP 的产生 ${ }^{[23]}$.

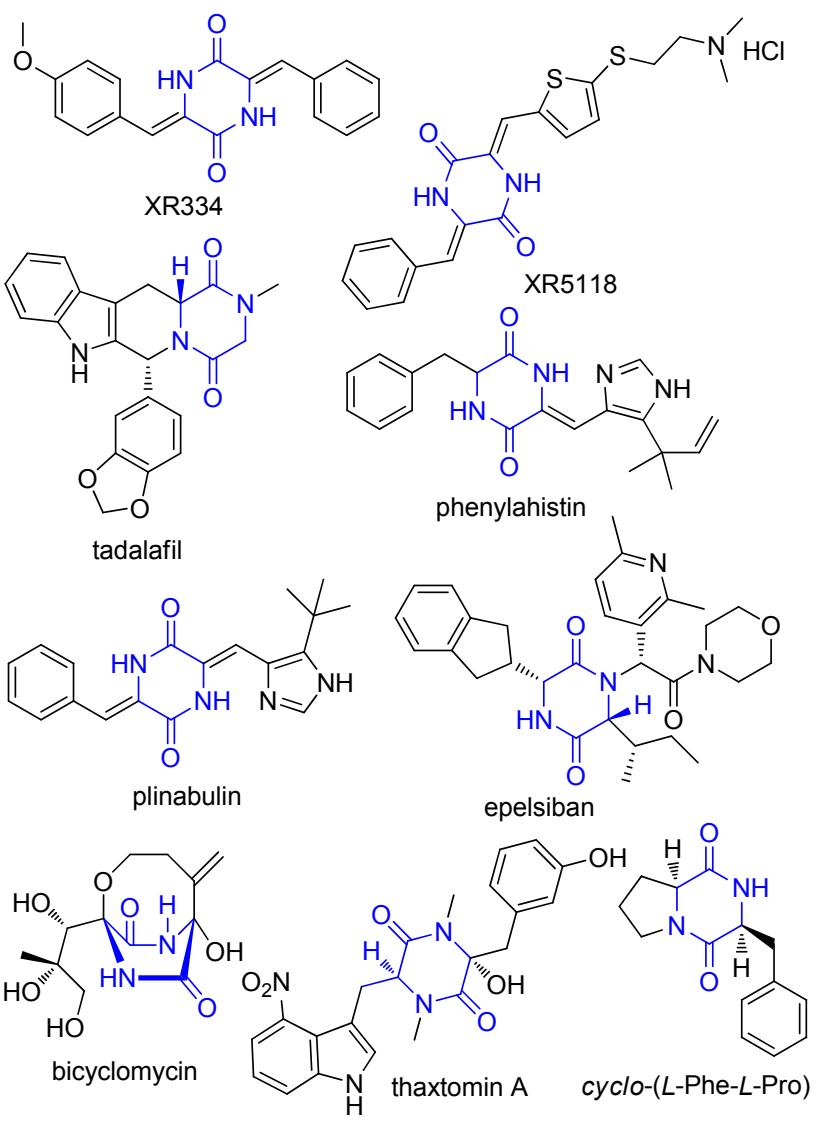

图 1 具多种生物活性的二酮哌嗪类化合物

Figure 1 Chemical structures of DKPs with diverse bioactivities

合成可作为药物先导物的二酮哌嗪类化合物已日 益引起人们的关注. 近年来国内外研究人员在 DKPs 有 机合成方面开展了大量的研究工作, 建立了组合化学、 固相合成和液相合成等一系列方法与技术，成功获得了 具有多种药理活性的 $\mathrm{DKPs}^{[1,24]}$. 天然产物的生物合成 研究是拓宽其化学结构多样性的一个极为有效的途
径 ${ }^{[25]}$. 与其有机合成相比, DKPs 的生物合成研究起步 较晚，但随着现代生物技术和高通量测序技术的飞速发 展，人们对 DKPs 生物合成分子机制与酶学机理的认识 不断深入, 若干 DKPs 类化合物的生物合成途径也已被 阐明，通常可分为非酶催化和酶催化途径.

非酶催化途径是指肽链的环化是自发的，未经酶的 参与. 如普遍存在于高等哺乳动物中枢神经系统的 cyclo- $(L-H i s-L-P r o)^{[59]}$. 酶催化途径可分为非核糖体肽 合成酶(non-ribosomal peptide synthetases, NRPSs)和环 二肽合酶(cyclodipeptide synthases, CDPSs)生物合成途 径两大类 ${ }^{[27,28]}$. 目前多数报道的 DKPs 是通过 NRPS 途 径合成或是 NRPS 途径中的副产物. 典型的 NRPSs 是一 类多酶复合物，由不同模块组成，每个模块负责将一个 氨基酸缩合到肽链上. 一个基本的延伸模块至少含有 3 个功能结构域 ${ }^{[29]}$ : 负责底物识别和活化的腺苷化结构 域(adenylation domain, A domain), 通过硫酯键加载活化 底物的肽基载体蛋白结构域(peptide carrier protein domain, PCP domain), 以及负责肽键缩合的缩合结构域 (condensation domain, C domain). 此外, 某些模块还包 含其它修饰功能结构域, 如甲基化结构域 ( $N$-methylation domain, $\mathrm{M}$ domain)和异构化结构域(epimerization domain, E domain), 最后通常由负责肽链解离的硫酯酶 结构域(thioesterase domain, TE domain)将聚肽链从 PCP 上解离下来. 相比之下, CDPS 途径是新发现的一种与 NRPS 途径不同的 DKPs 类化合物生物合成途径. Gondry 和 Sylvie 课题组 ${ }^{[27]}$ 于 2002 年在诺尔斯氏链霉菌 (Streptomyces noursei)中克隆了白诺氏菌素(albonoursin) 的生物合成基因簇, 发现其中 $a l b C$ 基因编码的大小仅 为 239 aa 的酶能够催化 albonoursin 骨架结构 cyclo( $L$-Phe- $L-L e u)$ 的合成. 这个小分子蛋白与 NRPSs 几乎没 有同源性，并与任何已知功能蛋白均无相似性 ${ }^{[39]}$. 2009 年, $\mathrm{AlbC}$ 首次在体外被鉴定为环二肽合酶, 成为第一个 功能被阐明的 $\mathrm{CDPS}^{[32]}$. 与 NRPSs 不同的是, CDPSs 本 身不具备活化氨基酸的催化活性, 而是直接以细胞内氨 酰-tRNAs (aa-tRNAs) 作为底物, 竞争蛋白质生物合成所 需的 aa-tRNAs 合成次级代谢产物, 将初级代谢和次级 代谢直接关联. 本文对近年来国内外有关环二肽合酶 (CDPSs)生物合成途径研究进展进行了综述.

\section{CDPSs 亚家族的分类}

CDPSs 通常是由 200 300 个氨基酸残基组成的小 分子蛋白，大部分 CDPSs 序列同源性都很低，氨基酸一 致性小于 30\%. 截至 2017 年 6 月，通过序列同源性检索 鉴定出约 800 个 CDPSs 编码基因, 且其数量在稳步增 加. 它们分布在所有域(domain)中, 但主要集中在 3 个 细菌门(Actinobacteria, Firmicutes 和 Proteobacteria). 这 其中, 约 400 个 CDPSs 来源于放线菌门 ${ }^{[34]}$.

CDPSs 分布在系统发育树的两个主要分支上(图 2). 


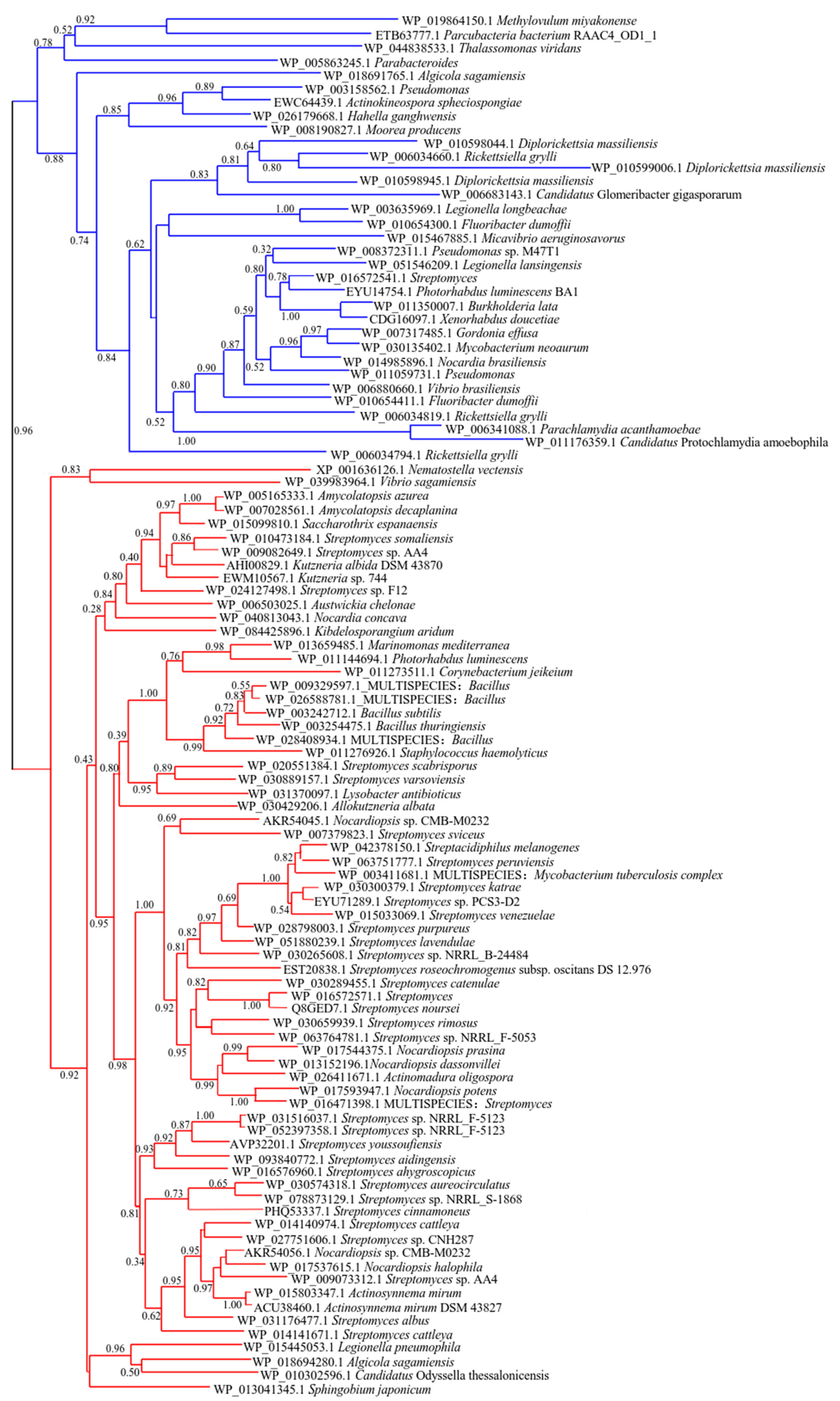

图 2 CDPSs 系统进化树分析

Figure 2 Phylogenetic analysis of selected CDPSs

The tree was generated using the PhyML program (v3.1) based on the maximum likelihood method. CDPSs' names consist of the corresponding accession numbers in the NCBI database and the host organisms in which they were found. The two main branches corresponding to the XYP and NYH subfamilies are shown in blue and red, respectively 
依据特定催化残基不同分为两大亚家族: NYH 亚家族 (含 “N40, Y202, H203”) 和 XYP 亚家族(含 “X40, Y202, P203”). 序列比对显示 Y202 残基在所有活性 CDPSs 中都严格保守. 在 NYH 亚家族中, $97 \%$ 的 CDPSs 的 N40 是保守的, H203 在 $95 \%$ 的 CDPSs 中保守. 在 XYP 亚家 族的 CDPSs 中, X40 可以是 Q $(38.5 \%), \mathrm{N}(25 \%), \mathrm{K}$ $(13.5 \%), \mathrm{S}(15.4 \%)$ 或 $\mathrm{A}(7.7 \%)^{[41 \mathrm{a}]}, \mathrm{P} 203$ 几乎是严格保守 的, 只有来源于 Parabacteroides 的 CDPS(WP 005863245.1)在相应位置为 $\mathrm{Q}^{[33]}$. 随着鉴定的 CDPSs 数 量的不断增加, 对其亚家族的分类也在不断调整与完 善.

\section{CDPSs 的结构及催化机制}

最早解析的三个 CDPSs 的晶体结构均属 NYH 亚家 族, 分别是来自 $S$. noursei 的 AlbC (PDB ID, 3OQV) ${ }^{[30]}$, Mycobacterium tuberculosis 的 Rv2275 (PDB ID, 2X9Q) ${ }^{[36 a]}$ 以及 Bacillus licheniformis 的 YvmC-Blic (PDB $\mathrm{ID}, 3 \mathrm{OQH})^{[49]}$ (图 $3 \mathrm{~A}$ ). $\mathrm{AlbC}$ 和 $\mathrm{YvmC}$ 为单体结构, Rv2275 为二聚体结构. 尽管这些 CDPSs 序列一致性低 于 $27 \%$, 但它们的晶体结构能较好地重叠, $\mathrm{rms}$ 偏差仅 为 $2.27 \AA$ (Rv2275 vs. AlbC, over $192 \mathrm{C}_{\alpha}$ atoms), $2.2 \AA$ (Rv2275 vs. YvmC, over $211 \mathrm{C}_{\alpha}$ atoms) 以及 $2.46 \AA$ (AlbC vs. YvmC, over $180 \mathrm{C}_{\alpha}$ atoms). 每个 CDPS 单体重叠性较 好的结构为 5 条 $\beta$ 折叠 ( $\beta 3-\beta 7)$ 及 2 个 $\alpha$ 螺旋 $(\alpha 2$ 和 $\alpha 4)$, 其 中 $\beta 3-\beta 5, \alpha 2$ 和 $\alpha 4$ 组成 Rossmann 折叠结构域 ${ }^{[35 \mathrm{~d}]}$ (图 3A). 三个 CDPSs 都具有一个相似的表面结合口袋(surfaceaccessible pocket) P1, 且口袋内保守的催化残基也重叠 性较好(除 Y202 外). CDPSs 的结构与 class-I aa-tRNA 合 成酶(aa-tRSs)相似，尤其类似于 class-Ic TyrRSs 和 $\mathrm{TrpRSs}^{[36]}$ (图 3B), 均具有 Rossmann 折叠结构域, CDPSs 的 P1 口袋与二者的氨酰基结合口袋位置相对应 ${ }^{[46]}$. CDPSs 和 I 型 aaRSs 之间也存在若干关键差异: CDPSs 不具有 I 型 aa-tRSs 中 tRNA-结合结构域, 其依靠表面的 氨基酸残基结合 tRNA; TyrRSs 和 TrpRSs 一般形成同源 二聚体, 两个活性位点位于二聚体交界面, 而 CDPSs 单 体即可有活性. 因此, CDPSs 可能由 I 型 aaRSs 进化而 来, 从而能以 aa-tRSs 的产物为底物催化酰胺键形成. 近期 Bourgeois 等 ${ }^{[41 a]}$ 解析了 XYP 亚家族的 3 个 CDPSs 的晶体结构, 分别为来自 Nocardia brasiliensis 的 NbraCDPS, Rickettsiella grylli 的 Rgry-CDPS 及 Fluoribacter dumoffii 的 Fdum-CDPS. 两个亚家族的 CDPSs 晶体结构 差异性集中体现在 Rossmann 折叠结构域的前半部分 $(\alpha 1, \beta 2, \beta 6, \beta 7, \alpha 8)$, 其中 $\alpha 8$ 的空间位置在两个亚家族 CDPSs 中都不保守, 而且它的长度在 XYP- CDPSs 中更 长, 二者 Rossmann 折叠结构域的后半部分 $(\alpha 2, \alpha 4-\alpha 7$,
A

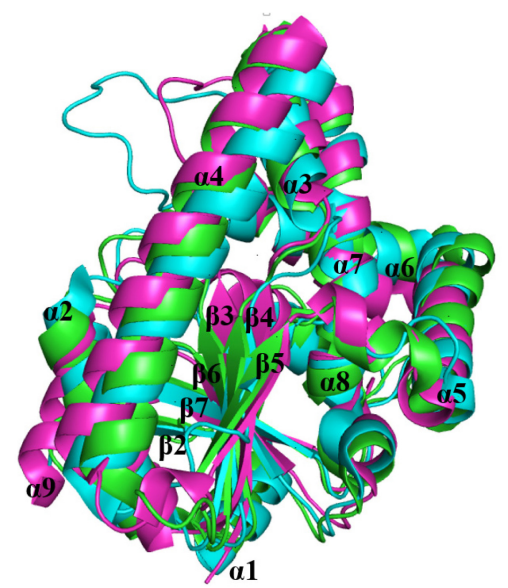

B

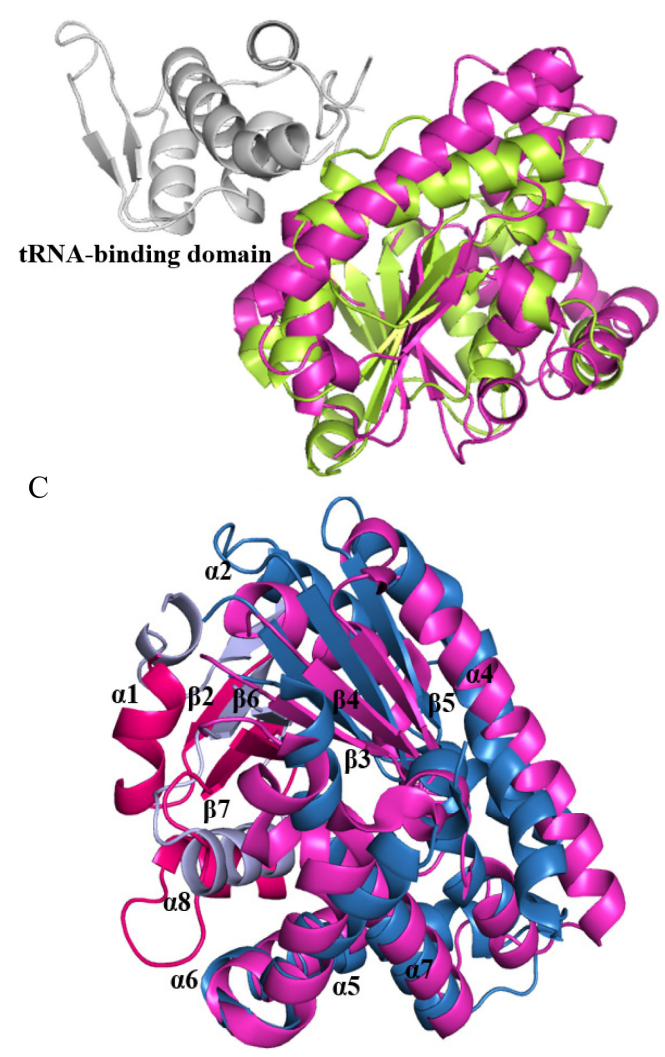

图 3 CDPSs 晶体结构的比较

Figure 3 Comparison of the crystal structures of CDPSs (A) Superimposition of the cartoon structures of AlbC (PDB ID, 3OQV; light magenta), Rv2275 (PDB ID, 2X9Q; green), and YvmC (PDB ID, $3 \mathrm{OQH}$; cyan). (B) Superimposition of the cartoon structures of AlbC and TyrRS of M. jannaschii (PDB ID, 1J1U). AlbC is in light magenta; TyrRS is in lemon; a C-terminal domain involved in tRNA-binding and anticodon recognition coloured in gray. (C) Superimposition of the cartoon structures of AlbC and Rgry-CDPS (PDB ID, 5MLP). The first half of the Rossmann fold of AlbC is in hot pink and Rgry-CDPS is in light blue; the second half of the Rossmann fold of AlbC is in light magenta and Rgry-CDPS is in sky blue

$\beta 3-\beta 5$ )则重叠性较好(图 3C). 关键催化残基(S37，Y202, Y178 和 E182)的空间位置在两个亚家族是相同的, 这 说明两个亚家族的催化机制可能是一致的 ${ }^{[41 a]}$. 
$\mathrm{AlbC}$ 的相关结构研究揭示了 CDPSs 可能的催化机 制为: 以 Phe-tRNA ${ }^{\text {Phe }}$ 和 Leu-tRNA ${ }^{\text {Leu }} / P h e-t R N A^{\text {Phe }}$ 为底 物, 通过一个连续的乒乓反应(Ping-pang reaction)合成 环二肽 ${ }^{[37 c]}$ (Scheme 1). 以合成 cyclo-(L-Phe- $\left.L-P h e\right)$ 为例. 首先, 第一个 Phe-tRNA ${ }^{\text {Phe }}$ 进入 $\mathrm{AlbC}$ 的 P1 口袋, tRNA 上带负电的核糖磷酸与 $\mathrm{AlbC}$ 的 $\alpha 4$ 螺旋上带正电的氨基 酸残基相互作用 ${ }^{[37]}$, 其苯丙氨酰基部分与 E182 和 Y178 侧链差基之间的氢键作用使其固定于 P1 中, 随后 S37 的羟基亲核攻击 Phe-tRNA ${ }^{\mathrm{Phe}}$ 的酯羰基, 氨酰基部分转 移到保守的 S37 残基上形成苯丙氨酰-AlbC 中间体. 之 后, 由 CL1 (catalytic loop 1: residues 36-43), CL2 (catalytic loop 2: residues 202-207), $\alpha 6 \mathrm{C}$ 末端(residues 152

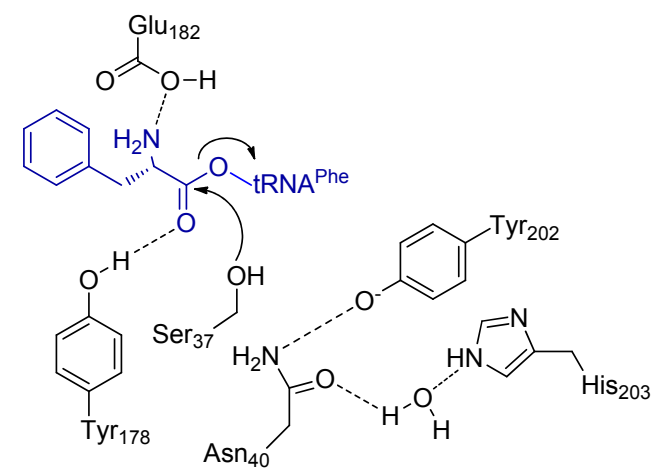

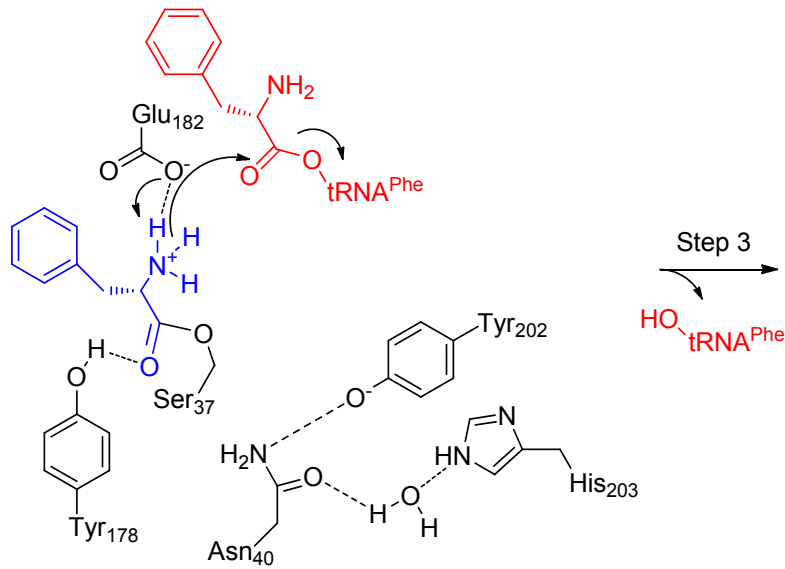

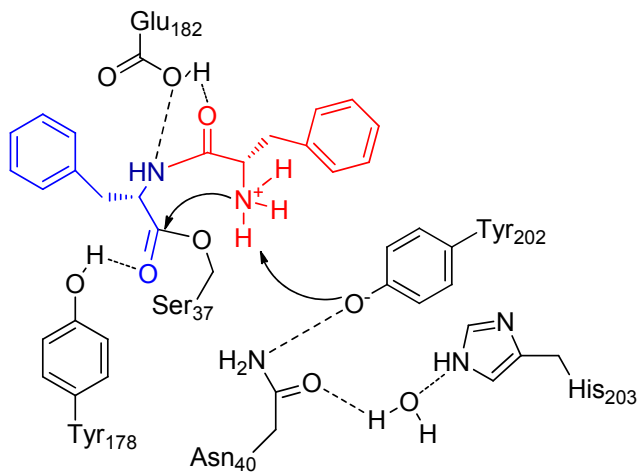<smiles>O=C1N[C@H](Cc2ccccc2)C(=O)N[C@@H]1Cc1ccccc1</smiles>

cyclo-(L-Phe-L-Phe)
159)和 $\alpha 7$ 中部(residues: 175 183)形成一个可容纳第二 个 aa-tRNA 的 P2 口袋. 第二个 Phe-tRNA ${ }^{\text {Phe }}$ 的 tRNA 结 构部分与 $\mathrm{AlbC}$ 的 $\alpha 6-\alpha 7$ 相互作用，其氨酰基部分进入 P2 口袋, E182 将苯丙氨酰-AlbC 中间体的氨基氮去质子 化，使其可以攻击第二个 Phe-tRNA ${ }^{\text {Phe }}$ 的酯羰基，形成 二肽基-AlbC 中间体. 最后, Y202 去质子化二肽基-AlbC 中间体的氨基氮, 进行分子内环化, 最终形成 $\mathrm{cFF}^{[26,56]}$. 此过程中, N40 和 H203 与水分子形成氢键网络，对 P2 口袋的稳定和催化残基的精确定位具有重要作用 ${ }^{[35]}$

\section{CDPSs 与 aa-tRNAs 底物作用的分子机制}

\subsection{CDPSs 特异识别两个底物的决定因素}

目前由 18 种天然氨基酸(除 Asp 及 Lys 之外)与

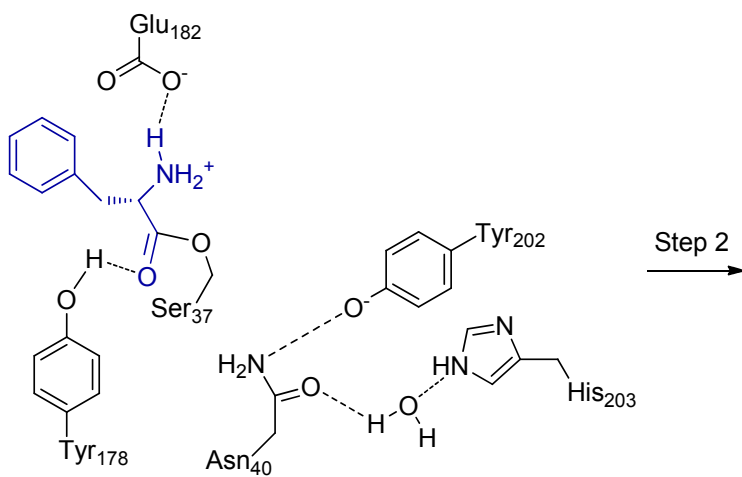

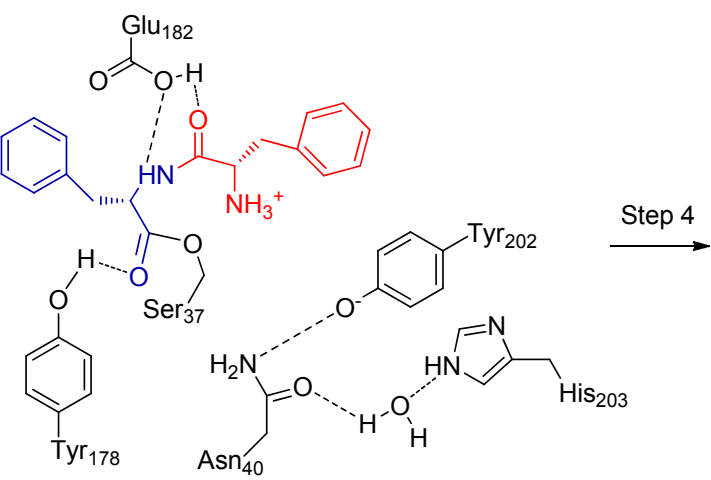

图式 $1 \mathrm{AlbC}$ 催化产生 cyclo-( $L$-Phe- $L$-Phe) 的分子机制[37c]

Scheme 1 Molecular mechanism of $\operatorname{cyclo}$-( $L$-Phe- $L$-Phe) formation catalyzed by AlbC 
tRNAs 结合形成的氨酰-tRNAs 作为底物产生的 75 种环 二肽中, 多数含有疏水性氨基酸, 未检测到酸性 Asp 及 碱性 Lys 残基, 最近的报道中有检测到 Arg 残基 ${ }^{[31]}$. 研 究人员发现大多数 CDPSs 似乎首先特异性识别 aatRNAs 的氨酰基 ${ }^{[37]}$, 与此一致, AlbC 负责合成 cyclo( $L$-Phe- $L$-Xaa), 载有 $D$-Phe 的 tRNAs 不被 AlbC 转化, 这 表明只有 $L$ 型氨基酸可作为 $\mathrm{AlbC}$ 的底物 ${ }^{[46]}$. 同时, AlbC 优先识别疏水性氨基酸, 而不能识别带电或极性的氨基 酸. 2014 年, Moutiez 等 ${ }^{[26]}$ 通过对携带野生型及突变型大 肠杆菌序列的 aa-tRNAs 进行生化实验, 研究了 AlbC 与 两个底物间的相互作用. 实验结果表明, AlbC 识别第一 个底物的特异性由其氨酰基部分决定, 识别第二个底物 的特异性涉及氨酰基部分和 tRNAs 的氨基酸接受茎序 列, 特别是 $\mathrm{N}^{1}-\mathrm{N}^{73}$ 碱基对. tRNAs 部分可用于激活氨基 酸的羧基, 促进氨酰基-酶中间体的形成, 并通过静电 相互作用增强底物与 CDPSs 的结合. CDPSs 底物结合口 袋中的氨基酸残基对识别底物具有非常重要的作用. 2011 年, Sauguet 等 ${ }^{[30]}$ 的实验结果显示 AlbC 的 P1 口袋 内 L200 突变为 Gln 导致产物由 cyclo- $(L-P h e-L-L e u)$ 转变 为 cyclo-( $L-\mathrm{Tyr}-L-\mathrm{Leu})$, 这直接证明了 P1 口袋内 L200 对识别第一个底物发挥关键作用. 最近, Yao 等 ${ }^{[51]}$ 发现 了首个以 $\mathrm{cWV}$ 为主要产物的来自于 Streptomyces youssoufiensis OUC6819 的 CDPS DmtB1, 能够合成 cyclo- $(L-$ Trp- $L$-Xaa) (Xaa = Val, Pro, Leu, Ile 和 Ala), 系 列定点突变结果显示位于 P1 口袋的 L185 突变为 Phe 后, 产物比例均发生明显变化, 主产物变为 $\mathrm{cWP}$, 即影 响了对第二个底物的识别, 位于 P2 口袋的 V205 被 Met 取代后, cWL 成为体内合成的主产物. 体外实验结果也 证实了 L185 及 V205 对第二个底物识别的重要作用.

\subsection{CDPSs 底物特异性预测}

随着鉴定的 CDPSs 序列数量日益增加, 如何预测 CDPSs 底物特异性, 合理推测其产物的问题摆在了研究 人员面前. 两个底物结合位点的揭示为第一种预测模型 的发展奠定了基础 ${ }^{[32]}$. 该预测模型的建立是基于已鉴 定功能的 CDPSs 中构成 P1 和 P2 口袋的残基的多序列 比对结果(表 1). 其中 P1 口袋含 8 个残基(33-35-65-67119-185-186-200, AlbC numbering), P2 口袋含 7 个残基 (152-155-156-159-204-206-207, AlbC numbering). 模型 将 CDPSs 分为六大类: 主产物分别为 cyclo- $(L-L e u-$ $L$-Leu) (cLL), cyclo-( $L$-Trp- $L$-Trp) (cWW), cyclo-( $L$-Cys$L$-Cys) (cCC), cyclo-( $L-\mathrm{Ala}-L-\mathrm{Glu})$ (cAE)的 CDPSs 以及 主产物中只确定了一个氨基酸 cyclo-(L-X-L-Glu) (cXE) 和 cyclo- $(L-\mathrm{Ala}-L-\mathrm{X})(\mathrm{cAX})$ 的 CDPSs. 自从这项研究以 来, 推定 CDPSs 的数量增加了 $50 \%$ 以上 ${ }^{[33 \sim 45]}$, 同时, 模 型也进一步得到了扩充, 增加了主产物为 cyclo- $(L-$
Tyr- $L$-Tyr) (cYY), cyclo-( $L$-Leu- $L-X)$ (cFX), cyclo-( $L$-Trp$L-\mathrm{X})(\mathrm{cWX})$ 和 cyclo- $(L-\mathrm{Cys}-L-\mathrm{X})(\mathrm{cCX})$ 等的分类 ${ }^{[31]}$. 然 而, 研究人员的实验结果显示许多 CDPSs 的预测产物 与其实际产物相差甚远, 如在 $\mathrm{Li}$ 等 ${ }^{[50]}$ 的研究中, 模型预 测显示 WP_078950527.1、WP_019889609.1 和 WP_063768158.1 这三个 CDPSs 的产物为 cFX, 而其实 际产物均为 cWW. 该预测模型需通过鉴定更多的 CDPSs 的结构及结合口袋中的氨基酸残基，同时需考虑 tRNA 与底物间相互作用来得到进一步的完善.

表 1 CDPSs 表面结合口袋 P1、P2 内氨基酸残基序列比对结 果 $^{a}$

Table 1 Specificity groups identified and their consensus motifs of $\mathrm{P} 1$ and $\mathrm{P} 2$ determined from characterized CDPSs

\begin{tabular}{c}
$\begin{array}{c}\text { Specificity } \\
\text { group (*) }\end{array}$ \\
\hline $\begin{array}{c}\text { cLL (NYH) } \\
(7 / 123)\end{array}$ \\
$\begin{array}{c}(8 / 22) \\
\text { cWW (NYH) } \\
(8 / 60) \\
\text { cXE (XY) } \\
(9 / 81) \\
\text { cAX (XY) } \\
(10 / 88)\end{array}$
\end{tabular}

${ }^{a}$ The numbers in brackets $(*)$ correspond to the number of CDPSs experimentally characterized $v s$. the total number of CDPSs in the group (Last up-date: June 2017 , Gondry et al. 2018 ${ }^{[40]}$; degenerated positions are indicated in gray.

\section{CDPS 生物合成途径合成 DKPs}

不同于 NRPSs 识别底物的多样性, 且某些 NRPSs 自身含有修饰氨基酸的结构域, CDPS 生物合成途径的 修饰发生在环二肽合成之后，由 CDPS 生物合成基因簇 中的后修饰酶基因对环二肽进行修饰 ${ }^{[39]}$.

目前国内外已研究的经 CDPS 途径合成的二酮哌嗪 类化合物共报道了 6 例 ${ }^{[34]}$. 包括 albonoursin ${ }^{[40 a, 27,32] 、}$ mycocyclosin $^{[29,32,40]}$ 、pulcherriminic acid ${ }^{[41]}$, nocazine 族 nocazine XR334 和 nocazine $\mathrm{E}^{[60]}$ 、 bicyclomycin ${ }^{[54]}$ 以 及 drimentines ${ }^{[51]}$. 此外, 甲基化双色氨酸及 nocardioazines A 和 B 的合成途径也已有所研究 ${ }^{[38,44]}$.

\subsection{Albonoursin 生物合成途径}

来源于 Streptomyces noursei 的 albonoursin 生物合成 基因簇包含 3 个基因: 编码 CDPS 的 $a l b C$ 及编码环二肽 
氧化酶(cyclic dipeptide oxidase, CDO)的 albA 和 $a l b B$. AlbC 催化 Phe-tRNA ${ }^{\text {Phe }}$ 和 Leu-tRNA ${ }^{\text {Leu 缩合形成 } c y c l o-~}$ ( $L$-Phe-L-Leu), 随后通过 AlbA/AlbB 氧化产生 albonoursin(图 5) ${ }^{[27]}$. CDO 是黄素依赖性 $\alpha, \beta$-脱氢酶, 具 有保守的 FMN 结合位点, 底物特异性低, 可催化 albonoursin 中两个双键的形成 ${ }^{[00 a]}$. 单独的 $a l b A$ 表达并 不能产生具活性的 $\mathrm{CDO}$, 其必须要求 $a l b B$ 的共同参与. AlbB 可能通过作为电子受体或催化 AlbA 的翻译后修饰 发挥作用, 其确切的反应机理尚未阐明[27,32].

\subsection{Pulcherriminic acid 生物合成途径}

来源于 Bacillus subtilis 的 pulcherriminic acid 的生物 合成基因簇包含一个编码 CDPS 的 $y v m C$ 基因和一个编 码细胞色素 P450 酶的基因 cyp134A1 (cypX). YvmC 以两 分子的 Leu-tRNA ${ }^{\mathrm{Leu}}$ 为底物合成 cyclo-( $L$-Leu- $L$-Leu), 细 胞色素 Cyp134A1(CypX)催化发生三步氧化形成双 $N$-氧 化物, 即发生着基化及连续两次脱水或直接的电子转移
反应，同时伴随着 DKP 环的芳构化(图 6) ${ }^{[41]}$. Pulcherriminic acid 能够通过其两个异羟肜酸部分螯合 $\mathrm{Fe}^{3+}$ ，推 测其可以作为抗生素或铁载体 ${ }^{[41 c]}$.

\subsection{Mycocyclosin 生物合成途径}

来源于 M. tuberculosis 的 mycocyclosin 生物合成基 因簇包含 2 个基因: 编码 CDPS 的 $r v 2275$ 与编码细胞色 素 P450 酶的 $r v 2276$ (cyp121). Rv2275 以两分子的 Tyr-tRNA ${ }^{\text {Tyr }}$ 为底物合成 cyclo-( $\left.L-T y r-L-T y r\right), C Y P 121$ 在 体外反应中催化环二肽酪氨酸侧链的两个 $\beta-C$ 之间的 $\mathrm{C}-\mathrm{C}$ 单键形成, 产生 mycocyclosin ${ }^{[36 a, 40 b]}$ (图 7). Mycocyclosin 的结构中两个酪氨酸侧链位于 DKP 杂环的同 一侧, 这在酶催化过程中需要通过旋转 $\mathrm{C} \alpha-\mathrm{C} \beta$ 键而实 现. CYP121 与一系列唑类抗真菌药物(例如克霉唑, 咪 康唑)紧密结合, 表明它可能可以作为 M. tuberculosis 等 结核病原体中抗生素的新靶点 ${ }^{[48]}$.

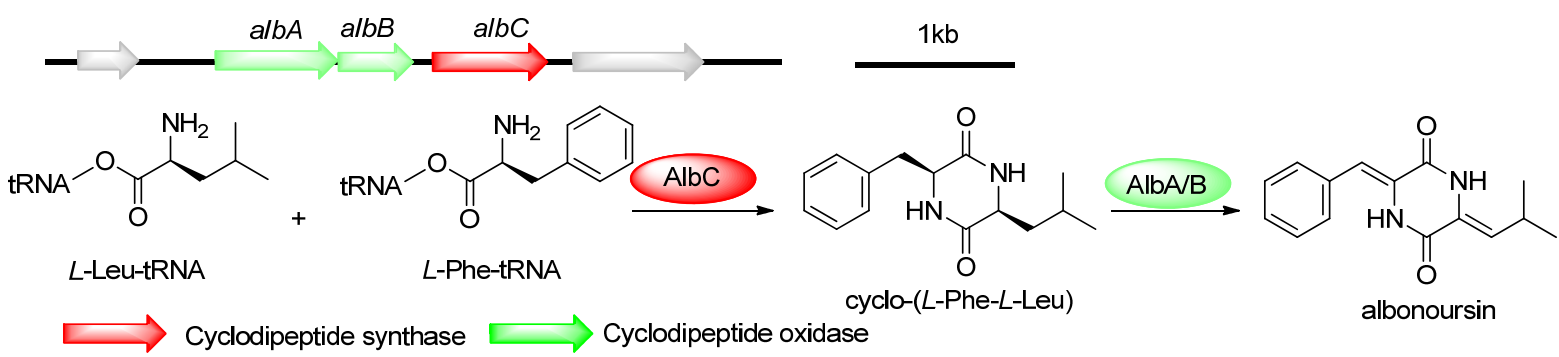

图 5 Albonoursin 的生物合成途径及其生物合成基因簇

Figure 5 Biosynthetic pathways and gene clusters of albonoursin

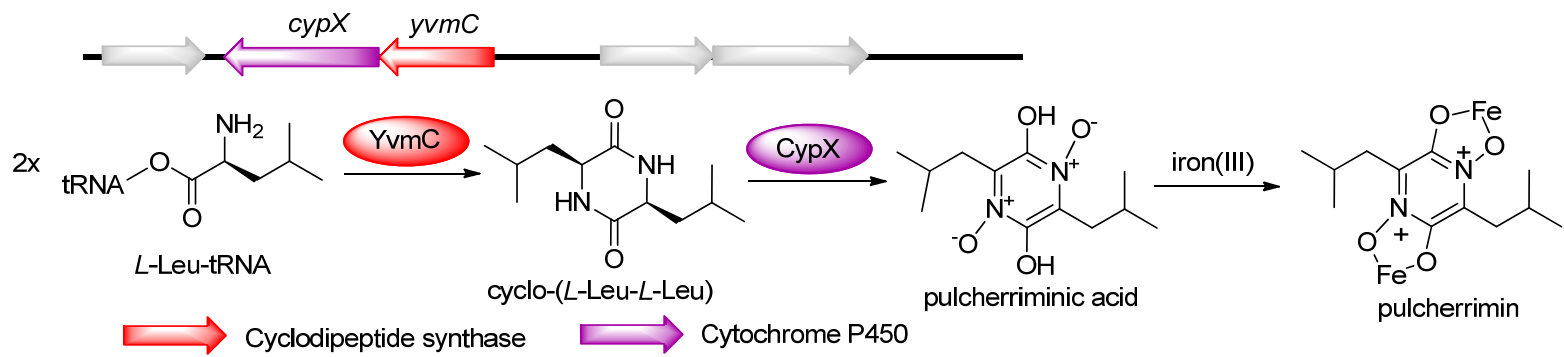

图 6 Pulcherrimin 的生物合成途径及其生物合成基因簇

Figure 6 Biosynthetic pathways and gene clusters of pulcherrimin

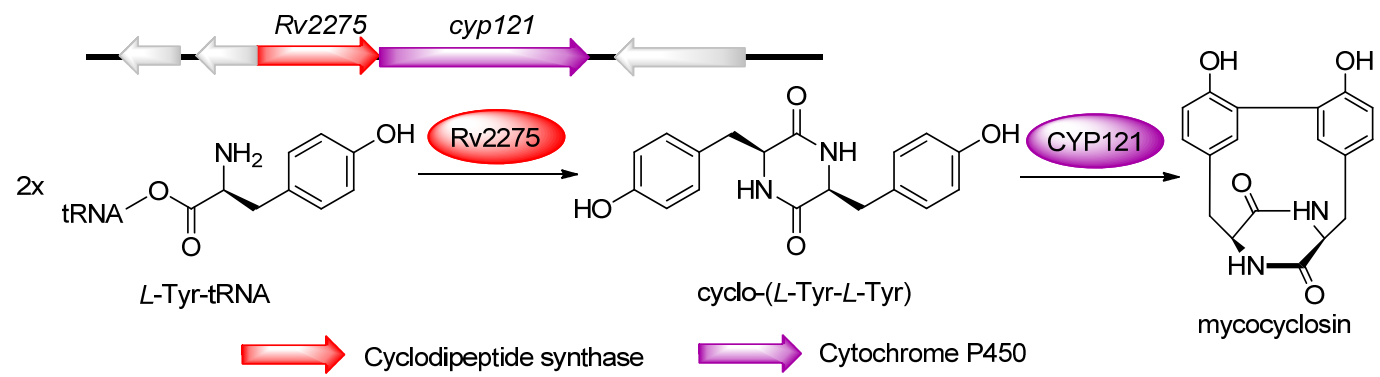

图 7 Mycocyclosin 的生物合成途径及其生物合成基因簇

Figure 7 Biosynthetic pathways and gene clusters of mycocyclosin 


\subsection{Nocazine XR334 和 nocazine E 生物合成途径}

来源于 Nocardiopsis dassonvillei 和 Nocardiopsis $a l b a$ 的 nocazine XR334 和 nocazine $\mathrm{E}$ 生物合成基因簇包 含 4 个基因: 编码 CDPS 的Ndas_1148、编码 CDO 同源 基因的 Ndas_1146/Ndas_1147 及编码 $O$-甲基转移酶 (methyltransferase, MT)的 Ndas_1149. Giessen 等 ${ }^{[42,60]}$ 通 过体外实验证明了 Ndas_1148 催化合成 cyclo- $(L-$ Phe- $L$-Tyr), Ndas_1146/Ndas_1147 催化一次或两次 $\alpha, \beta$ 脱氢, Ndas_1149 进一步催化酪氨酸羟甲基化形成 nocazine XR334 和 nocazine $\mathrm{E}$ (图 8). 该基因簇中 $\mathrm{CDO}$ 的上游还存在一个可能的 $O$-甲基转移酶基因 Ndas_1145.

\subsection{Bicyclomycin 生物合成途径}

双环霉素 bicyclomycin 含有高度氧化的双环, 是一 种广谱抗生素. 其生物合成基因簇广泛分布在放线菌门 和变形菌门, 甚至也存在于近百株条件致病菌绿脓杆菌 (Pseudomonas aeruginosa) 的基因组中 ${ }^{[58]}$. 其生物合成途 径中共包含 7 个酶: 1 个环二肽合酶 BcmA, 6 个氧化还 原酶(包括 5 个 $\alpha$-酮戊二酸/ $\mathrm{Fe}^{2+}$ 依赖性双加氧酶 $\mathrm{BcmB}$, $\mathrm{BcmC}, \mathrm{BcmE}, \mathrm{BcmF}$ 和 $\mathrm{BcmG}$, 以及 1 个细胞色素 $\mathrm{P} 450$ 单加氧酶 BcmD) (图 9). 首先, BcmA 以 Leu-tRNA ${ }^{\mathrm{Leu}}$ 和 Ile-tRNA ${ }^{\text {Ile }}$ 为底物催化合成 cyclo-( $L$-Leu- $L$-Ile); 随后, 分别经 $\mathrm{BcmE}, \mathrm{BcmC}$ 和 $\mathrm{BcmG}$ 催化 C-3, C-2', C-3'位上羟 基化. 接着 $\mathrm{BcmB}$ 催化 $\mathrm{C} 1-\mathrm{C} 1$ '脱氢形成双键环氧化, 进 一步氧杂桥环的形成是否由 $\mathrm{BcmB}$ 催化或自发进行还未
确定. $\mathrm{BcmD}$ 负责在桥联的 $\mathrm{sp}^{3}$-杂化的碳中心上加载叔 差基, $\mathrm{BcmF}$ 催化产生环外双键最终形成双环霉素 ${ }^{[54]}$.

\subsection{Drimentines 类化合物生物合成途径}

本课题组采用异源表达、基因阻断、互补和高表达 以及体外生化实验等手段对 3 个同源的含有 CDPS 的基 因簇 $d m t 1-3$ 进行了研究, 揭示了一类杂合异戊烯化 DKPs 类化合物 drimentines 的生物合成途径. 以 drimentine $\mathrm{G}$ 为例, 环二肽合酶 DmtB1 首先催化产生 cyclo-( $L$-Trp- $L$-Val)，接着 PSL (phytoene-synthase-like) 家族异戊烯转移酶 $\mathrm{DmtC} 1$ 将法尼基焦磷酸 (farnesyl pyrophosphate, FPP)加载到 cyclo-( $L-$ Trp- $L-V a l)$ 的 C-3 位 上, 形成 pre-drimentine $\mathrm{G}$, 然后经膜蛋白萜烯环化酶 DmtA1 催化双键起始的环化反应形成 drimentine $\mathrm{G}$ (图 $10)^{[51]}$.

此外, 其他两个 CDPS 生物合成途径也已有所研究, 它们的环二肽产物特征为 cyclo-( $L$-Trp-L-Xaa). Actinosynnema mirum 基因组中含有一个编码 CDPS 基因 Amir_4627、一个编码 $N$-甲基转移酶基因 Amir_4628 以 及一个编码脂肪酰基-CoA 连接酶基因 Amir_4626 组成 的基因簇 ${ }^{[38,43]}$. Amir_4627 催化产生 cyclo-( $L$-Trp- $\left.L-T r p\right)$, 它被甲基转移酶 Amir_4628 修饰产生带有一个或两个 $\mathrm{N}$-甲基化的环二肽．在体内及体外实验中，脂肪酰基$\mathrm{CoA}$ 连接酶 Amir_4626 均被验证没有发挥功能 ${ }^{[38]}$. 来源 于 Nocardiopsis sp. CMB-M0232 的 nocardioazines A/B生 物合成所需的基因分布在两个基因簇内，包含编码

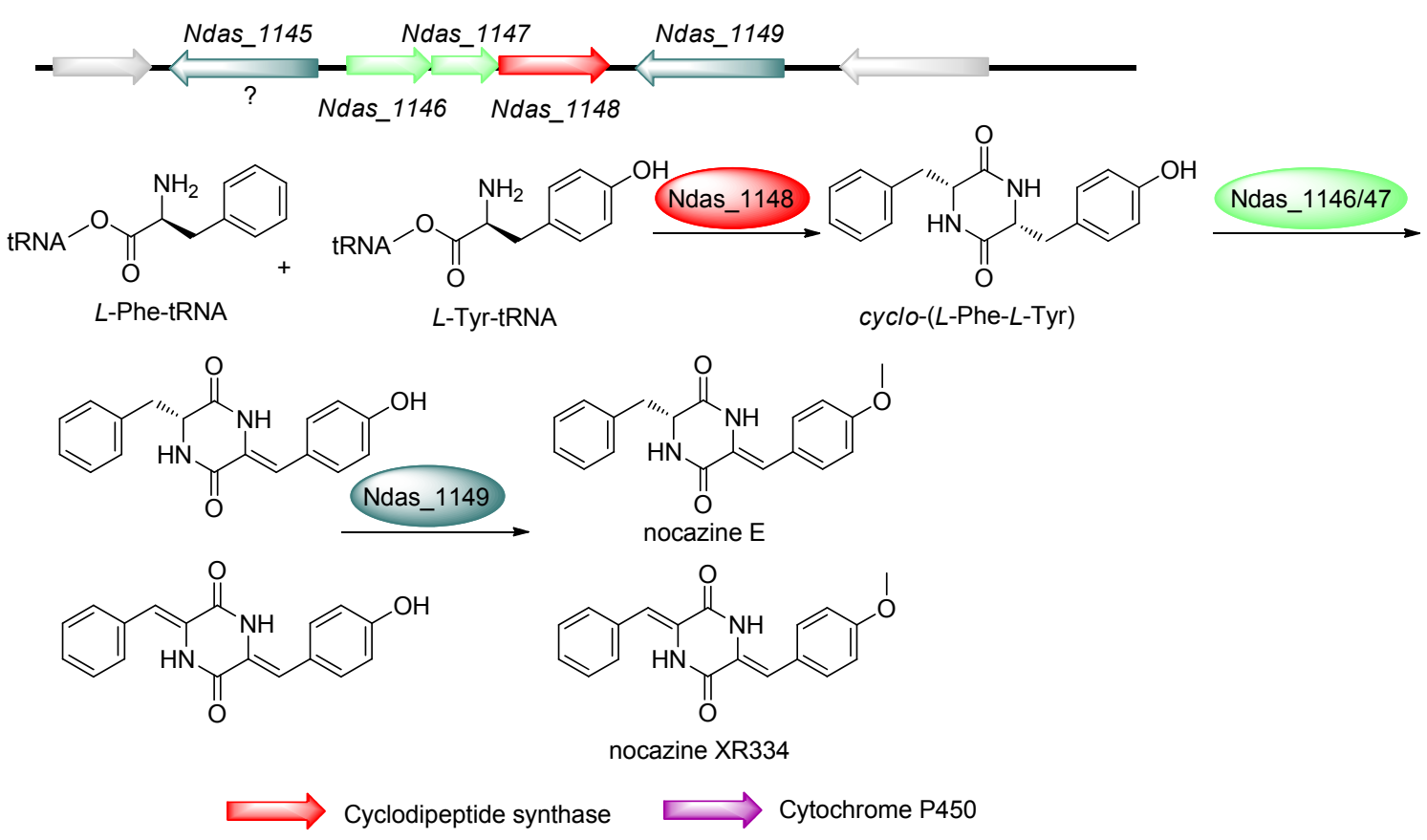

图 8 Nocazine family 的生物合成途径及其生物合成基因簇

Figure 8 Biosynthetic pathways and gene clusters of nocazine family The function of gene Ndas_1145 remains to be clarified 

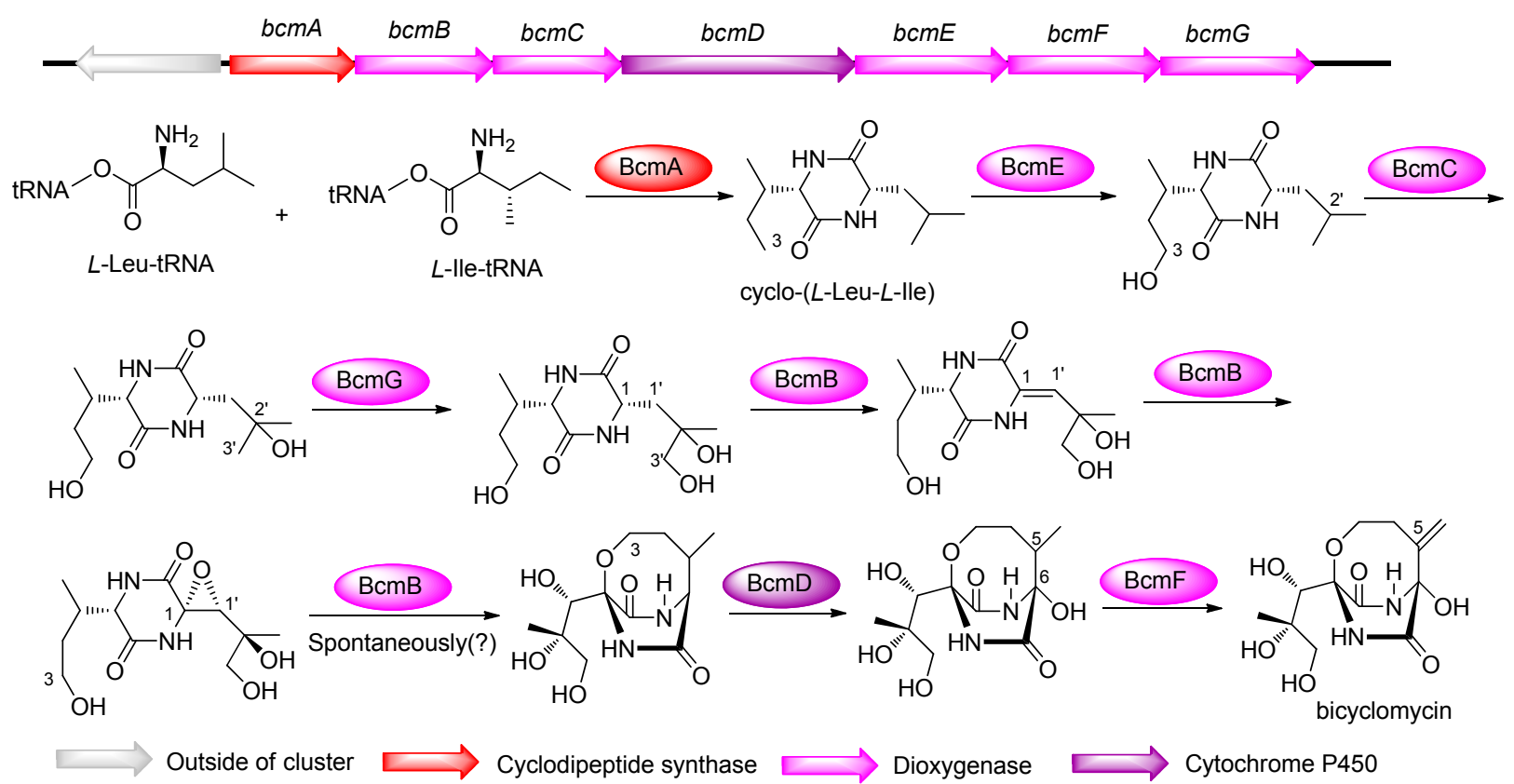

图 9 Bicyclomycin 的生物合成途径及其生物合成基因簇

Figure 9 Biosynthetic pathways and gene clusters of bicyclomycin

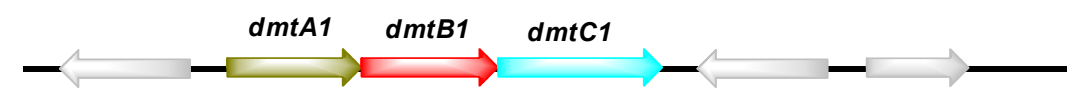<smiles>CCCCCCCCCCC(=O)OCc1c[nH]c2ccccc12</smiles>

L-Trp-tRNA

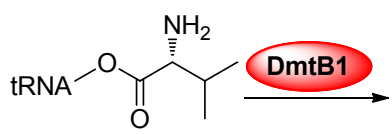

L-Val-tRNA<smiles>CC(C)=CCOc1ccccc1</smiles>

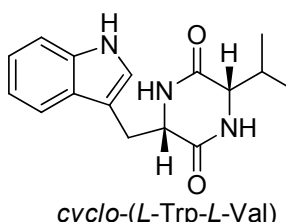

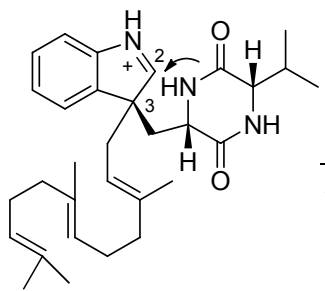

$\underset{\text { Spontaneously(?) }}{\stackrel{D m t C 1}{\longrightarrow}}$<smiles>CCCC12CCCCC1(CCC)C(C)(C(C)C)NC2=O</smiles>

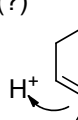<smiles>C1CC2CCC1C2</smiles>
pre-drimentines $\mathrm{G}$
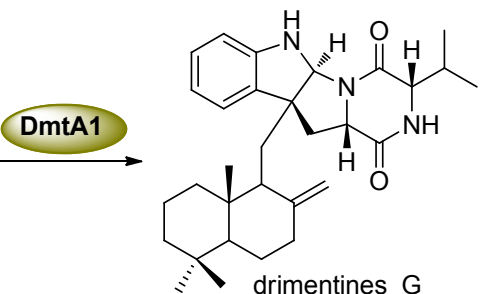

Outside of cluster

$\square$ Membrane terpene cyclase

Cyclodipeptide synthase

Prenyltransferase

图 10 Drimentines 类化合物的生物合成途径及其生物合成基因簇

Figure 10 Biosynthetic pathways and gene clusters of drimentines

CDPS 的 NozA、可能参与后修饰的异戊烯转移酶 NozC、 甲基转移酶 NozB 及细胞色素 P450酶 NozD 及 NozE, 编 码后修饰酶的基因具体功能还未阐明 ${ }^{[34,44]}$.

\section{CDPS 合成 DKPs 结构的合理设计}

对 CDPS 生物合成途径的产物进行结构多样性的合 理设计, 以期获得结构新颖或良好生物学活性的药物先 
导物已成为近年来 CDPS 领域研究的热点之一. 目前主 要有两种方法可合理修饰肽天然产物结构.

第一种方法为改变 CDPS 催化产生 DKPs 骨架的多 样性. 由于 CDPSs 的特异性与 tRNAs 结合的氨酰基部 分及其 tRNAs 序列有关, 因此可以通过改变 tRNAs 携带 的氨基酸序列或改变结合氨基酸的 tRNAs 序列来实现. 后者可通过体外转录或采用突变技术将特定序列变化 引入tRNAs 中, 在不影响其完整结构的同时产生序列多 样性的 tRNAs. 前者则可改变组成氨基酸的种类、数量 或连接性. 由于最初发现的 CDPSs 只能催化天然 aatRNAs, 因此, 研究人员使用非常见氨基酸(noncanonical Amino Acids, ncAAs)代替培养基中的天然氨 基酸, 结合使用营养缺陷型表达宿主, 产生非天然 $\mathrm{CDPs}^{[45]}$. 截至目前, 已发现 26 个 ncAAs 可作为 CDPSs 的底物, 从而产生约 200 个非天然环二肽 ${ }^{[25]}$.

第二种方法为在 DKP 骨架上通过修饰酶引入不同 的修饰 ${ }^{[47]}$. 在 CDPS 途径开展组合生物合成时, 可优先 考虑 CDPS 生物合成基因簇中的修饰酶. CDPS 基因簇

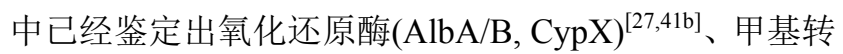
移酶(Ndas_1149, Amir_4628) ${ }^{[42,38]}$ 、异戊烯基转移酶

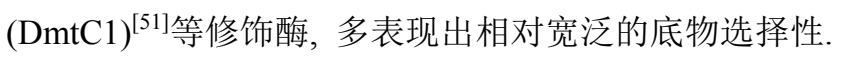
Skinnider 等 ${ }^{[43]}$ 对 739 个 CDPS 基因簇进行分析, 发现 CDPS 周围还存在大量 $N$-乙酰基转移酶、糖基转移酶等 修饰酶基因, 这表明将来乙酰化、糖基化的 DKPs 化合 物会被不断发现, 为进一步采用组合生物合成和合成生 物学策略以增加天然产物多样性提供了重要功能元件.

\section{6 总结与展望}

二酮哌嗪类化合物以其丰富的生物活性引起了人 们极大的关注, 自 2002 年首次发现后, tRNA 依赖性环 二肽合酶(CDPSs)生物合成途径已在国内外研究领域取 得了显著进展. 但已阐明的 CDPS 生物合成途径的数量 远远低于 CDPSs 的多样性. 随着 CDPSs 编码基因不断 发现及生物合成途径的逐步揭示, 更多新颖的后修饰酶 将被挖掘和表征. 通过组合生物合成等研究进行结构多 样性的合理设计, 获得结构丰富的具生物活性的 DKPs 类化合物将尤为重要. 在此过程中, 由于异戊烯化的天 然产物通常具有明显不同于其非异戊烯化前体的生物 活性, 这使得异戊烯转移酶对于构建具有生物活性的 “非天然” 天然产物的合成途径有很大潜力 ${ }^{[51 ~ 53,57]}$. 同 时, 关于 CDPS 的一些其他问题有待于解答, 包括是否 有特异性因素决定 CDPS 会产生一系列 CDPs 还是只有 一种化合物 ${ }^{[2]}$ ? 通过 P1、P2 关键残基预测环二肽产物 的模型, 未将 tRNA 与底物相互作用考虑进来, 还不能 普遍应用, 能否形成更加完善的预测方法? 对 P1、P2
口袋选择底物的特异性这一问题的认知还在不断更新 及发展 ${ }^{[31]}$. 未来亚家族的分类是否还会有所扩充及调 整, 仍不得而知. 但冊庸置疑的是, 这些棘手待解决问 题将迅速推动着 CDPS 生物合成途径的研究前行, 为最 终实现人为创造和生产高活性 DKPs 化合物提供重要的 理论依据.

\section{References}

[1] Borthwick, A. D. Chem. Rev. 2012, 112, 3641.

[2] Giessen, T. W.; Marahiel, M. A. Int. J. Mol. Sci. 2014, 15, 14610.

[3] Menegatti, S.; Hussain, M.; Naik, A. D. Biotechnol. Bioeng. 2013, $110,857$.

[4] de Carvalho, M. P.; Abraham, W. R. Curr. Med. Chem. 2012, 19, 3564.

[5] Kohna, H.; Widger, W. Curr. Drug Targets: Infect. Disord. 2005, 5, 273.

[6] Musetti, R.; Polizzotto, R.; Vecchione, A. Micron 2007, 38, 643.

[7] Ström, K.; Sjögren, J.; Broberg, A. Appl. Environ. Microbiol. 2002, $68,4322$.

[8] Rodriguez, P. L.; Carrasco, L. J. Virol. 1992, 66, 1971.

[9] Kanoh, K.; Kohno, S.; Katada, J. Bull. Agric. Chem. Soc. Jpn. 1999, 63, 1130.

[10] Kanzaki, H.; Yanagisawa, S.; Nitoda, T. Bull. Agric. Chem. Soc. Jpn. 2004, 68, 2341.

[11] Waring, P.; Beaver, J. Gen. Pharmacol. 1996, 27, 1311.

[12] Cornacchia, C.; Cacciatore, I.; Baldassarre, L. Mini-Rev. Med. Chem. 2012, 12, 2 .

[13] Pérezpicaso, L.; Olivo, H. F.; Argotteramos, R. Bioorg. Med. Chem. Lett. 2012, 22, 7048.

[14] Bolognesi, M. L.; Ai, T. H.; Staderini, M. ChemMedChem 2010, 5, 1324.

[15] Song, M. K.; Hwang, I. K.; Rosenthal, M. J. Exp. Biol. Med. 2003, 228,1338

[16] Wang, G. X. Chin. J. Thromb. Hemostasis. 2011, 17, 234 (in Chinese). (王贵金金，血栓与止血学, 2011, 17, 234.)

[17] Sun, T. W.; Ding, Z. P.; Wang, S. X. Chin. J. Mar. Drug. 2016, 4, 79 (in Chinese). (孙天文，丁忠鹏，王世潇，中国海洋药物, 2016, 4, 79.)

[18] Martins, M. B.; Carvalho, I. Tetrahedron 2007, 63, 9923.

[19] Zhang, H.; Ning, X.; Hang, H. Org. Lett. 2013, 15, 5670.

[20] Wen, L.; Liu, Q. Q.; Yang, Q. H. Prog. Mod. Biomed. 2012, 119, 2894.

[21] Rajesh Shinghal, M. D.; Allison Barnes, M. S.; Mahar, K. M. $J$. Sex. Med. 2013, 10, 2506.

[22] Charlton, P. A.; Faint, R. W.; Bent, F. Thromb. Haemostasis. 1996 $75,808$.

[23] Park, D. K.; Lee, K. E.; Baek, C. H. J. Bacteriol. 2006, 188, 2214.

[24] (a) Wyatt, P. G.; Allen, M. J.; Borthwick, A. D. Bioorg. Med. Chem. Lett. 2005, 15, 2579.

(b) Fischer, P. M. J. Pept. Sci. 2003, 9, 9.

(c) O'Neill, J. C.; Blackwell, H. E. Comb. Chem. High Throughput Screening. 2007, 10, 857.

(d) Merwe, E. V. D.; Huang, D.; Peterson, D.; Kilian, G.; Milne, P. J.; Venter, M. V. D. Peptides 2008, 29, 1305.

[25] Canu, N.; Belin, P.; Thai, R. Angew. Chem., Int. Ed. 2018, 57, 3118.

[26] Moutiez, M.; Seguin, J.; Fonvielle, M.; Belin, P.; Jacques, I. B.; Favry, E.; Arthur, M.; Gondry, M. Nucleic Acids Res. 2014, 42, 7247.

[27] Lautru, S.; Gondry, M.; Genet, R. Chem. Biol. 2002, 9, 1355.

[28] Moutiez, M.; Belin, P.; Gondry, M. Chem. Rev. 2017, 117, 5578.

[29] Li, W. L.; Xia, J. Microb. China 2014, 41, 111 (in Chinese). (李文利, 夏娟, 微生物学通报, 2014, 41, 111.)

[30] Sauguet, L.; Moutiez, M.; Li, Y.; Belin, P.; Seguin, J.; Le Du, M.H.; 
Thai, R.; Masson, C.; Fonvielle, M.; Pernodet, J. L. Nucleic Acids Res. 2011, 39, 4475 .

[31] Gondry, M.; Jacques, I. B.; Thai, R. Front. Microb. 2018, 9.

[32] Gondry, M.; Sauguet, L.; Belin, P. Nat. Chem. Biol. 2009, 5, 414.

[33] Jacques, I. B.; Moutiez, M.; Witwinowski, J. Nat. Chem. Biol. 2015, 11, 721.

[34] (a) Brockmeyer, K.; Li, S. M. J. Nat. Prod. 2017, 80, 2917.

(b) Mukai, T.; Reynolds, N. M.; Crnković, A. Life 2017, 7, 8.

(c) Alqahtani, N.; Porwal, S. K.; James, E. D. Org. Biomol. Chem. 2015, 13, 7177 .

(d) Sievers, F.; Wilm, A.; Dineen, D.; Gibson, T.J.; Karplus, K.; Li, W.; Lopez, R.; McWilliam, H.;Remmert, M.; Soding, J. Mol. Syst. Biol. 2011, 7, 539 .

[35] (a) Bonnefond, L.; Arai, T.; Sakaguchi, Y. Proc. Natl. Acad. Sci. U. S. A. 2011, 108, 3912 .

(b) Yaremchuk, A.; Kriklivyi, I.; Tukalo, M. EMBO J. 2002, 21, 3829 .

(c) Jacques, I.; Seguin, J.; Moutiez, M. New Biotechnol. 2014, 31, S74.

(d) Cusack, S.; Berthet-Colominas, C.; Härtlein, M.; Nassar, N.; Leberman, R. Nature 1990, 347, 249.

[36] (a) Vetting, M. W.; Hegde, S. S.; Blanchard, J. S. Nat. Chem. Biol. 2010, 6, 797.

(b) Han, W.; Gao, J. F. Chem. Bioeng. 2013, 30, 17 (in Chinese). (韩伟，高菊芳，化学与生物工程, 2013, 30, 17.)

[37] (a) Seguin, J.; Moutiez, M.; Li, Y. Chem. Biol. 2011, 18, 1362. (b) Minelli, A.; Bellezza, I.; Grottelli, S.; Galli, F. Amino Acids 2008, 35, 283

(c) Moutiez, M.; Schmitt, E.; Seguin, J. Nat. Commun. 2014, 5, 5141.

[38] Giessen, T. W.; von Tesmar, A. M.; Marahiel, M. A. Biochemistry 2013, 52,4274

[39] (a) Aravind, L.; De, S. R. F.; Iyer, L. M. Biol. Direct 2010, 5, 48.

(b) Belin, P.; Moutiez, M.; Lautru, S. Nat. Prod. Rep. 2012, 29, 961. (c) Roback, P.; Beard, J.; Baumann, D. Nucleic Acids Res. 2007, 35, 5085 .

[40] (a) Gondry, M.; Lautru, S.; Fusai, G. Eur. J. Biochem. 2001, 268, 1712 .

(b) Belin, P.; Le Du, M.H.; Fielding, A.; Lequin, O.; Jacquet, M.; Charbonnier, J. B.; Lecoq, A.;Thai, R.; Courcon, M.; Masson, C. Proc. Natl. Acad. Sci. U. S. A. 2009, 106, 7426.

(c) Leys, D.; Mowat, C. G.; Mclean, K. J. J. Biol. Chem. 2003, 278, 5141.

(d) Seward, H. E.; Roujeinikova, A.; Mclean, K. J. J. Biol. Chem. 2006, 281, 39437.

[41] (a) Bourgeois, G.; Seguin, J.; Babin, M. J. Struct. Biol. 2018.

(b) Cryle, M. J.; Bell, S. G.; Schlichting, I. Biochemistry 2010, 49,
7282.

(c) Tang, M. R.; Sternberg, D.; Behr, R. K. Ind. Biotechnol. 2006, 2, 66.

[42] Zhang, Q.; Li, S.; Chen, Y.; Tian, X.; Zhang, H.; Zhang, G.; Zhu, Y.; Zhang, S.; Zhang, W.;Zhang, C. J. Antibiot. 2013, 66, 31

[43] Skinnider, M. A.; Johnston, C. W.; Merwin, N. J. BMC Genomics. 2018, 19, 45

[44] James, E. D.; Knuckley, B.; Alqahtani, N. ACS Synth. Biol. 2016, 5 , 547.

[45] Johnson, J. A.; Lu, Y. Y.; Van Devente, J. A. Curr. Opin. Chem. Biol. 2010, 14, 774.

[46] Giessen, T. W.; Altegoer, F.; Nebel, A. J.; Steinbach, R. M.; Bange, G.; Marahiel, M. A. Angew. Chem., Int. Ed. 2015, 54, 2492.

[47] Giessen, T. W.; Marahiel, M. A. Front. Microb. 2015, 6, 785.

[48] McLean, K. J.; Cheesman, M.R.; Rivers, S.L.; Richmond, A.; Leys, D.; Chapman, S. K.; Reid, G. A.; Price, N. C.; Kelly, S. M.; Clarkson, J.; Smith, W. E.; Munro, A. W. J. Inorg. Biochem. 2002, 91, 527.

[49] Bonnefond, L.; Arai, T.; Sakaguchi, Y. Proc. Natl. Acad. Sci. U. S. A. 2011, 108, 3912.

[50] Liu, J.; Yu, H.; Li, S. M. Appl. Microbiol. Biotechnol. 2018, 102, 4435.

[51] Yao, T. T.; Liu, J.; Liu, Z. Z.; Li, T.; Li, H. Y.; Che, Q.; Zhu, T. J.; Li, D. H.; Gu, Q. Q.; Li, W. L. Nat. Commun. 2018, 9, 4091.

[52] (a) Li, S. M. ChemInform 2010, 27, 57.

(b) Xu, W.; Gavia, D. J.; Tang, Y. Nat. Prod. Rep. 2014, 31, 1474

(c) Alkhalaf, L. M.; Ryan, K. S. Chem. Biol. 2015, 22, 317.

(d) Walsh, C. T. ACS Chem. Biol. 2014, 9, 2718.

[53] Fan, A.; Winkelblech, J.; Li, S. M. Appl. Microbiol. Biotechnol. 2015, 99, 7399.

[54] (a) Meng, S.; Han, W.; Zhao, J.; Jian, X. H.; Pan, H. X.; Tang, G. L. Angew. Chem., Int. Ed. 2018, 57, 719.

(b) Patteson, J.; Cai, W.; Johnson, R. A.; Santa, M. K.; Li, B. Biochemistry 2017, 57, 61 .

[55] Kohn, H.; Widger, W. Curr. Drug Targets: Infect. Disord. 2005, 5 , 273.

[56] Schmitt, E.; Bourgeois, G.; Gondry, M.; Aleksandrov, A. Sci. Rep. 2018, 8,7031

[57] Wunsch, C.; Mundt, K.; Li, S. M. Appl. Microbiol. Biotechnol. 2015, 99, 4213.

[58] Vior, N. M.; Lacret, R.; Chandra, G.; Dorairaj, S.; Trick, M. \& Truman, A. W. Appl. Environ. Microbiol. 2018, 84(9), UNSP e02828-17.

[59] Prasad, C. Peptides 1995, 16, 151.

[60] Giessen, T. W.; von Tesmar, A. M.; Marahiel, M. A. Chem. Biol. 2013, 20, 828 . 